\title{
Vision Decreased, CTCAE
}

National Cancer Institute

\section{Source}

National Cancer Institute. Vision Decreased, CTCAE. NCI Thesaurus. Code C143196.

A disorder characterized by a decrease in visual acuity. 